\title{
Inability to predict postpartum hemorrhage: insights from Egyptian intervention data
}

\author{
Ndola Prata ${ }^{{ }^{*}}$, Sabry Hamza ${ }^{2}$, Suzanne Bell ${ }^{1}$, Deborah Karasek ${ }^{1}$, Farnaz Vahidnia ${ }^{1}$ and Martine Holston ${ }^{3}$
}

\begin{abstract}
Background: Knowledge on how well we can predict primary postpartum hemorrhage (PPH) can help policy makers and health providers design current delivery protocols and PPH case management. The purpose of this paper is to identify risk factors and determine predictive probabilities of those risk factors for primary PPH among women expecting singleton vaginal deliveries in Egypt.

Methods: From a prospective cohort study, 2510 pregnant women were recruited over a six-month period in Egypt in 2004. PPH was defined as blood loss $\geq 500 \mathrm{ml}$. Measures of blood loss were made every 20 minutes for the first 4 hours after delivery using a calibrated under the buttocks drape. Using all variables available in the patients' charts, we divided them in ante-partum and intra-partum factors. We employed logistic regression to analyze socio-demographic, medical and past obstetric history, and labor and delivery outcomes as potential PPH risk factors. Post-model predicted probabilities were estimated using the identified risk factors.

Results: We found a total of 93 cases of primary PPH. In multivariate models, ante-partum hemoglobin, history of previous PPH, labor augmentation and prolonged labor were significantly associated with PPH. Post model probability estimates showed that even among women with three or more risk factors, PPH could only be predicted in $10 \%$ of the cases.
\end{abstract}

Conclusions: The predictive probability of ante-partum and intra-partum risk factors for PPH is very low. Prevention of PPH to all women is highly recommended.

\section{Background} Introduction

Primary postpartum hemorrhage (PPH) is the single largest contributor to maternal mortality worldwide. Throughout Africa and Asia, hemorrhage accounts for $30 \%$ or more of all maternal deaths, most of which is $\mathrm{PPH}$ [1]. Even if effective antenatal screening existed, hemorrhage often occurs in women with no identifiable antepartum risk factors. Risk factors in the intra-partum period may provide opportunity for intervention, or for active management in the early stages of PPH.

Despite the severe burden of PPH, few studies have examined risk factors predicting PPH in developing countries. The primary objective of this study is to investigate the ability to predict PPH by early screening of

\footnotetext{
* Correspondence: ndola@berkeley.edu

1 Bixby Center for Population, Health and Sustainability, School of Public Health, University of California at Berkeley, 229 Warren Hall, UC-Berkeley, Berkeley, CA 94720-7360, USA

Full list of author information is available at the end of the article
}

women with selected risk factors. We hypothesize that a combination of ante-partum and intra-partum risk factors will be associated with incidence of $\mathrm{PPH}$, and that these factors will have utility for screening and clinical management of labor. The secondary objective of this study is to identify the components of active management of the third stage of labor (AMTSL) that have the greatest impact on PPH incidence. AMSTL is a component of internationally accepted clinical protocol for obstetric management consisting of four components: use of uterotonics, uterine massage, early cord clamping, and cord traction. The importance of AMSTL in PPH is well established, yet the relative importance of each component of the process has not been examined.

\section{Previous Research}

Previous research has identified demographic, ante-partum, and intra-partum risk factors that are associated with risk of hemorrhage, but these associations are not predictive. In addition, the majority of these studies focus 
on women in the United States or Europe who may face different delivery circumstances from women in developing countries. An extensive literature review on PubMed that investigated ante-partum and intra-partum risk factors for PPH was carried out. All of the risk factors found are described below; citations are only for the most recent article published on the topic.

Investigators have established myriad demographic, ante-partum, and intra-partum risk factors. Demographic risk factors associated with excessive blood loss (greater than 500 or $1000 \mathrm{ml}$ ) in the first 24 hour after vaginal delivery include non-white ethnicity [2], and older age [3]. Among ante-partum risk factors, history of PPH [4], history of blood disorders [2], nulliparity [5], low parity [6], grand multiparty [7], high blood pressure [8], ante-partum hemorrhage [9], multiple pregnancy [3], fewer than four prenatal visits [10], lack of iron supplementation/anemia [3], over distended uterus [5], pregnancy induced hypertension [11], and increased maternal BMI [12] have been significantly associated with PPH in previous studies. Intra-partum risk factors may indicate a different point of intervention than ante-partum factors. Past studies have shown preterm birth [7], episiotomy or genital tract trauma [11], labor augmentation or instrumental delivery [8], use of oxytocics for induction or augmentation [7], induction of labor [8], abnormal fetal presentation [2], manual removal of placenta or retained placenta [11], uterine atony [4], coagulopathy [13], placenta previa or accreta [14], perineal tear [15], intra-partum hemorrhage [5], non-use of oxytocics after delivery [16], birthweight [10], placental weight [7], and perinatal death [17] to be significantly associated with $\mathrm{PPH}$.

Prolonged labor is consistently associated with $\mathrm{PPH}$ as well, although studies differ on a meaningful threshold for each stage. Stones et al. associated labor of over 12 hours with increased risk of PPH [18]. While multiple studies associate prolonged $1^{\text {st }}$ and $2^{\text {nd }}$ stage of labor with increased risk of $\mathrm{PPH}$, the magnitude of association for the $3^{\text {rd }}$ stage appears to be pronounced [2,5,7-9,11,14,19-26].

Despite all that is known about PPH risk factors, risk factors associated with primary PPH are not useful in predicting patients who will continue to bleed after firstline therapy [27]. And while previous studies have identified significant associations among ante-partum and intra-partum risk factors, Tsu's paper (1993) is the only published work examining predictive probability of screening for PPH. While predictive values were less than $7 \%$, she found that screening tests for maternal height, parity, and obstetric history could identify one third of PPH cases [28].

\section{Methods}

We conducted a secondary data analysis using data from prospective, hospital based operations research in Egypt in 2006. The objective of the original operations research was to compare the current protocol for the AMTSL with the use of $600 \mu \mathrm{g}$ of misoprostol. The conclusion was that misoprostol should be considered for inclusion in the AMTSL protocol where oxytocin and or ergometrine are not consistently and appropriately used during the $3^{\text {rd }}$ stage of labor. The original study was analyzed as a pre-/post-intervention study. In the current study, we analyzed all women who experienced PPH as 'cases' and all women who did not experience PPH as 'controls.' Details on design data, collection, and results of the original study are reported elsewhere [29]. Over a 6-month period, 2532 pregnant women were recruited into the study from three university hospitals. Inclusion criteria were: anticipated singleton vaginal delivery, gestational age greater than 36 weeks, and ability to give informed consent. Women who delivered by cesarean section or women with missing information on delivery type were excluded from this analysis, leaving a total of 2510 women.

The primary outcome of interests was incidence of PPH. In accordance with international clinical protocol, $\mathrm{PPH}$ was defined as blood loss greater than $500 \mathrm{ml}$ during the first 4 hours after delivery. Following delivery and the clamping of the umbilical cord, a calibrated drape was placed under the women's buttocks for blood loss measurement. This drape remained under the women's buttocks for 4 hours, during which time blood loss was read cumulatively every 20 minutes. Total blood loss was established after the bleeding had stopped. In the original study, women in the misoprostol group were $70 \%$ less likely to bleed $500 \mathrm{ml}$ or more (OR $=0.30,95 \%$ CI $0.16-0.56)$ compared to those in the current practices group. In addition, the women in the misoprostol group needed additional interventions because of postpartum hemorrhage only $11 \%$ of the time, compared to $73 \%$ among the current practices group.

To evaluate the value of risk factors for screening and labor management, attending physicians collected both ante-partum and intra-partum information using questionnaires that were completed at the time of admission, during labor, after delivery for up to 4 hours, and before discharge. Variables collected at the time of admission for delivery include maternal age (30 years or older), education (literacy), nulliparity, previous antenatal care (no care or high number of visits compared), PPH in a previous pregnancy, history of obstetric complications, intact membranes, anemia, and cervical dilation. Anemia was measured by blood collected after enrollment, and defined as ante-partum hemoglobin at or below $11 \mathrm{mg} / \mathrm{dl}$.

Intra-partum variables include vaginal delivery with instruments, episiotomy, labor augmentation, retained placenta, vaginal tears, fetal macrosomia (> $3500 \mathrm{~g}$ ), length of $1^{\text {st }}$ and $2^{\text {nd }}$ stage, and absence of AMTSL. Additionally, 
the absence of each component of AMTSL was measured separately, including use of uterotonics in the $3^{\text {rd }}$ stage, early cord clamping, cord traction, and uterine massage.

Ethical review for the study was provided by the Committee for the Protection of Human Subjects at the University of California, Berkeley and the Egyptian ethics committees. The Healthy Mother Healthy Child Project, which was implemented by John Snow Inc. under United States Agency for International Development (USAID) Contract No. 263-C-00-98-0041-00, was responsible for study implementation. Venture Strategies for Health and Development (VSHD) donated the misoprostol used in the operations research (Misotac; Sigma Co., Moubarak industrial City, First Quarter Quesna, Egypt).

Data was entered using Epi-Info version 2002 (Centers for Disease Control and Prevention, Atlanta, Georgia, USA), and statistical analysis was performed with the STATA $^{\circledR}$ version 8.0 (StataCorp, LP, College Station, Texas, USA). We constructed separate, multiple logistic regression models for ante-partum and intra-partum variables associated with $\mathrm{PPH}$, but not as a stepwise regression. Model 1 included demographic and antepartum variables; Model 2 included intra-partum variables and one variable to represent AMTSL; Model 3 is a variation of Model 2 with AMTSL separated out by each component; and the final model, Model 4, was the combination of demographic/antepartum, intra-partum, and separated AMTSL factors. Separating each of the four components of AMTSL allowed us to assess the relative importance of each component. Odds ratios were provided as the measure of effect. Results from the final model, Model 4, were used in post-model estimation of predictive probability of $\mathrm{PPH}$. In addition, we created cumulative scores based on the number of risk factors $(1,2,3$, or $4+)$. Sensitivity and specificity were calculated for the cumulative risk factor probabilities and for the combined measure of AMTSL. Receiver operating curves (ROC) were derived from these sensitivity and specificity estimates. Significant associations were established at $\mathrm{p}$-values $<0.05$.

\section{Results}

The incidence of PPH among the 2510 singleton vaginal deliveries was $3.71 \%(n=93)$. The distribution of demographics, ante-partum, and intra-partum risk factors are listed in Table 1. Odds ratios from bivariable analyses of risk factors and incidence of $\mathrm{PPH}$ are reported along with associated p-values and 95\% confidence intervals (CIs). Among unadjusted ante-partum variables, history of $\mathrm{PPH}$ in a previous pregnancy increased the risk of PPH by almost 69 times. Women who had one antenatal care (ANC) visit, those with no care, and those with higher levels of care also had an increased risk of PPH. No other ante-partum risk factors were significant in bivariable logistic regressions.
Among intra-partum risk factors, episiotomy, labor augmentation, vaginal tears, macrosomia, and length of the first and second stage of labor were each associated with an increased odds of PPH. Women who did not receive AMTSL were 8 times more likely to have PPH. When assessed separately, omission of each component of AMTSL was also significantly associated with PPH risk.

Table 2 shows separate adjusted multivariable models for ante-partum risk factors (Model 1), intra-partum risk factors, (Models 2 and 3) and a full model (Model 4) containing both sets of variables. Components of AMTSL were included separately (Model 3 ) and together (Model 2) in intra-partum models. Each AMTSL component was considered individually in the full model. History of previous $\mathrm{PPH}(\mathrm{OR}=105.44,95 \% \mathrm{CI}$ 15.14-734.53), 2-3 ANC visits $(\mathrm{OR}=7.02,95 \%$ CI 1.49-33.01), and over 4 ANC visits $(\mathrm{OR}=10.63,95 \% \mathrm{CI} 2.30-49.03)$ each remained positively associated with increased odds of $\mathrm{PPH}$ in the antepartum only model. Additionally, a multivariable intrapartum model that considered the four components of AMTSL combined showed that labor augmentation with oxytocin (OR $=1.77,95 \%$ CI 1.11-2.81), prolonged labor (1-2.9 hours OR $=2.42$, 95\% CI 1.15-5.06; 3-4.9 hours OR $=3.25,95 \%$ CI $1.62-6.53 ; 5+$ hours $\mathrm{OR}=2.66,95 \% \mathrm{CI}$ $1.22-5.82)$, and AMTSL (OR $=105.44,95 \%$ CI 15.14734.53) were significantly associated with risk of PPH. When each component of AMTSL was included separately, fetal macrosomia $(\mathrm{OR}=1.59,95 \% \mathrm{CI} 1.01-2.50)$ became marginally significant. In this model, use of uterotonics during the $3^{\text {rd }}$ stage of labor was the only AMTSL component associated with $\mathrm{PPH}(\mathrm{OR}=9.74,95 \%$ CI 4.58 20.77). Episiotomy was marginally associated with $\mathrm{PPH}$ risk $(\mathrm{p}=0.08)$. Vaginal tears, uterine massage, cord traction, and early cord clamping, though significant in the unadjusted analysis, were not associated with PPH after controlling for other intra-partum risk factors.

In the full multivariable model (Model 4), which included both ante- and intra-partum variables, elevated number of ANC visits (2-3 visits OR $=5.89,95 \%$ CI 1.1330.62 ; 4+ visits OR $=7.43,95 \%$ CI 1.44-38.46), history of $\mathrm{PPH}(\mathrm{OR}=305.14,95 \%$ CI 48.02-1938.87), anemia (OR = $2.73,95 \% \mathrm{CI} 1.43-5.23)$, labor augmentation $(\mathrm{OR}=2.37$, 95\% CI 1.14-4.93), retained placenta $(\mathrm{OR}=21.68,95 \% \mathrm{CI}$ 4.41-106.54), and length of $1^{\text {st }}$ and $2^{\text {nd }}$ stage (3-4.9 hours: $\mathrm{OR}=4.93,95 \%$ CI $1.55-15.70 ; 5+$ hours: $\mathrm{OR}=5.75,95 \%$ CI 1.73-19.14) remained significantly associated with increased risk of PPH. Non-use of uterotonics in the $3^{\text {rd }}$ third stage (OR $=11.26,95 \%$ CI 3.91-32.47), and cord traction $(\mathrm{OR}=8.26,95 \% \mathrm{CI} 1.02-67.00)$ were the only components of AMSTL that remained significant in the full model.

We used post model probability estimates to predict the probability of developing PPH with each one of the statistically significant risk factors in Model 4 (Figure 1). 
Table 1 Distribution of ante-partum and intra-partum factors and crude odds ratios associated with PPH (blood loss $\geq 500 \mathrm{~mL}$ ) for vaginal deliveries

\begin{tabular}{ccccc} 
PPH & No PPH & OR & p-value & $95 \% \mathrm{Cl}$ \\
$93 \mathrm{~N}(\%)$ & $2417 \mathrm{~N}(\%)$ & & & \\
\hline
\end{tabular}

\section{Ante-Partum}

Age

$<30$

$30+$

Education

illiterate

literate

Parity

$$
\text { multiparous }
$$

nuliparous

Antenatal care

1 visit

No ANC

2-3 visits

$4+$ visits

History of PPH

None

Prior PPH

Previous obstetric complications

none
Other non-PPH

Membranes

ruptured

intact

Anemia

Ante-partum hemoglobine $>11 \mathrm{mg} / \mathrm{dl}$

Ante-partum hemoglobine $<=11 \mathrm{mg} / \mathrm{dl}$

Cervical dilation on admission

$$
\begin{aligned}
& \text { up to } 3 \mathrm{~cm} \\
& 4-7 \mathrm{~cm} \\
& >7 \mathrm{~cm}
\end{aligned}
$$

Intra-partum

Delivery

Spontaneous delivery

vaginal delivery with instruments

Episiotomy

no

yes

Labor augmentation

no

yes

Complete placenta expulsion

yes

no

Vaginal tears

no

yes

Fetal weights

$$
<3500 \mathrm{mg}
$$

$72(77.4)$

$21(22.6)$

$1,892(79.4)$

492 (20.6)

1.00

1.12

0.650

$(0.68,1.84)$

34 (37.8)

1,092 (45.8)

1, $295(54.2)$

1.00

$56(62.2)$

$1,524(64.85)$

1.39

0.137

$(0.90,2.14)$

$53(61.6)$

826 (35.15)

1.00

33 (38.4)

2 (2.3)

29 (33.3)

21 (24.1)

35 (40.2)

275 (12.0)

874 (38.1)

$548(23.9)$

$597(26.0)$

88 (94.6)

$5(5.4)$

2,415 (99.9)

$2(0.1)$

92 (98.9)

1 (1.1)

2,306 (95.4)

111 (4.6)

0.23

614 (25.7)

1,775 (74.3)

1.00

24 (26.1)

68 (73.9)

55 (74.3)

19 (25.7)

1,332 (77.8)

$380(22.2)$

1.00

1.21

$161(6.7)$

1.00

4 (4.3)

57 (62.0)

$1,548(64.8)$

1.48

$680(28.5)$

1.83

0.453

0.260

$(0.53,4.14)$

31 (33.7)

92 (98.9)

$1(1.1)$

2,411 (99.8)

$6(0.2)$

$34(37.0)$

58 (63.0)

1,328 (55.8)

$1,052(44.2)$

1,562 (64.7)

854 (35.3)

2,395 (99.5)

$13(0.5)$

2,216 (95.3)

$110(4.7)$

1,692 (71.7)

$54(59.3)$

1.00

$(1.22,22.63)$

$(1.93,33.76)$

$(13.13,358.51)$

$(0.03,1.63)$

$(0.61,1.57)$

$(0.71,2.07)$

$(0.64,5.27)$

1.00

4.37

0.174

$(0.52,36.65)$

1.00

2.15

$<0.001$

$(1.40,3.31)$

1.00

2.04

0.001

$(1.34,3.09)$

1.00

2.00

0.506

$(0.26,15.47)$

82 (89.1)

1.00

2.46

0.010

$(1.24,4.87)$ 
Table 1 Distribution of ante-partum and intra-partum factors and crude odds ratios associated with PPH (blood loss $? \geq ? 500 \mathrm{~mL}$ ) for vaginal deliveries (Continued)

\begin{tabular}{|c|c|c|c|c|c|}
\hline Macrosomia (> 3500 mg) & $37(40.1)$ & $667(28.3)$ & 1.74 & 0.011 & $(1.13,2.67)$ \\
\hline \multicolumn{6}{|l|}{ Length of 1 st and 2 nd stage } \\
\hline$<1$ hour & $10(11.0)$ & $634(26.7)$ & 1.00 & & \\
\hline $1-2.9$ hours & $27(29.7)$ & $670(28.2)$ & 2.55 & 0.012 & $(1.23,5.32)$ \\
\hline $3-4.9$ hours & $34(37.3)$ & $629(26.5)$ & 3.43 & 0.001 & $(1.68,7.00)$ \\
\hline $5+$ hours & $20(22.0)$ & $443(18.6)$ & 2.86 & 0.007 & $(1.33,6.17)$ \\
\hline \multicolumn{6}{|l|}{ AMTSL } \\
\hline Yes & $62(66.7)$ & $2,281(94.4)$ & 1.00 & & \\
\hline No & $31(33.3)$ & $136(5.63)$ & 8.39 & $<0.001$ & $(5.27,13.35)$ \\
\hline \multicolumn{6}{|l|}{ AMTSL components } \\
\hline \multicolumn{6}{|c|}{ Use of uterotonics in 3rd stage } \\
\hline yes & $78(83.9)$ & 2,333 (96.6) & 1.00 & & \\
\hline no & $15(16.1)$ & $83(3.4)$ & 5.40 & $<0.001$ & $(2.98,9.79)$ \\
\hline \multicolumn{6}{|l|}{ Early cord clamping } \\
\hline yes & $86(92.5)$ & $2,376(98.3)$ & 1.00 & & \\
\hline no & $7(7.5)$ & $41(1.7)$ & 4.72 & $<0.001$ & $(2.06,10.82)$ \\
\hline \multicolumn{6}{|l|}{ Cord traction } \\
\hline yes & $85(91.4)$ & 2,399 (99.3) & 1.00 & & \\
\hline no & $8(8.6)$ & $18(0.7)$ & 12.54 & $<0.001$ & $(5.31,29.66)$ \\
\hline \multicolumn{6}{|l|}{ Uterine massage } \\
\hline yes & $82(88.2)$ & 2,383 (98.6) & 1.00 & & \\
\hline no & $11(11.8)$ & $34(2.4)$ & 9.40 & $<0.001$ & $(4.60,19.21)$ \\
\hline
\end{tabular}

Table 2 Adjusted multivariable logistic regression models for ante-partum and intra-partum risk factors associated with PPH (blood loss $\geq 500 \mathrm{~mL}$ ) for vaginal deliveries

\begin{tabular}{|c|c|c|c|c|c|c|c|c|}
\hline & $\begin{array}{c}\text { Model } 1 \\
\text { antepartum }\end{array}$ & & $\begin{array}{c}\text { Model } 2 \\
\text { intra-partum }\end{array}$ & & $\begin{array}{l}\text { Model } 3 \\
\text { AMTSL }\end{array}$ & & $\begin{array}{c}\text { Model } 4 \\
\text { Full model }\end{array}$ & \\
\hline & OR for PPH & $95 \% \mathrm{Cl}$ & OR for PPH & $95 \% \mathrm{Cl}$ & OR for PPH & $95 \% \mathrm{Cl}$ & OR for PPH & $95 \% \mathrm{Cl}$ \\
\hline \multicolumn{9}{|l|}{ Ante-Partum } \\
\hline \multicolumn{9}{|l|}{ Age } \\
\hline$<30$ & 1.00 & & - & & - & & 1.00 & \\
\hline $30+$ & 1.47 & $\begin{array}{l}(0.75 \\
2.88)\end{array}$ & - & & - & & 2.04 & $\begin{array}{l}(0.92 \\
4.52)\end{array}$ \\
\hline \multicolumn{9}{|l|}{ Education } \\
\hline illiterate & 0.83 & & - & & - & & 1.00 & \\
\hline literate & 1.00 & $\begin{array}{l}(0.39, \\
1.79)\end{array}$ & - & & - & & 0.62 & $\begin{array}{l}(0.28, \\
1.42)\end{array}$ \\
\hline \multicolumn{9}{|l|}{ Parity } \\
\hline multiparous & 1.21 & & - & & - & & 1.00 & \\
\hline nuliparous & 1.00 & $\begin{array}{l}(0.67, \\
2.19)\end{array}$ & - & & - & & 0.84 & $\begin{array}{c}(0.40 \\
1.78)\end{array}$ \\
\hline \multicolumn{9}{|l|}{ Antenatal care } \\
\hline 1 visit & 1.00 & & - & & - & & 1.00 & \\
\hline No ANC & 2.67 & $\begin{array}{l}(0.58 \\
12.32)\end{array}$ & & & & & 1.61 & $\begin{array}{l}(0.30 \\
8.51)\end{array}$ \\
\hline $2-3$ visits & 7.02 & $\begin{array}{l}(1.49 \\
33.01)\end{array}$ & & & & & 5.89 & $\begin{array}{l}(1.13 \\
30.62)\end{array}$ \\
\hline $4+$ visits & 10.63 & $\begin{array}{r}(2.30 \\
49.03)\end{array}$ & - & & - & & 7.43 & $\begin{array}{l}(1.44 \\
38.46)\end{array}$ \\
\hline \multicolumn{9}{|l|}{ History of PPH } \\
\hline None & 1.00 & & - & & - & & 1.00 & \\
\hline
\end{tabular}


Table 2 Adjusted multivariable logistic regression models for ante-partum and intra-partum risk factors associated with PPH (blood loss ? ??500 $\mathrm{mL}$ ) for vaginal deliveries (Continued)

\begin{tabular}{|c|c|c|c|c|c|c|c|c|}
\hline Prior PPH & 105.44 & $\begin{array}{l}(15.14 \\
734.53)\end{array}$ & - & & - & & 305.14 & $\begin{array}{c}(48.02, \\
1938.87)\end{array}$ \\
\hline \multicolumn{9}{|l|}{ Previous obstetric complications } \\
\hline none & 1.00 & & - & & - & & 1.00 & \\
\hline prior non-PPH complications & 0.26 & $\begin{array}{l}(0.04 \\
1.84)\end{array}$ & - & & - & & 0.25 & $\begin{array}{l}(0.02 \\
3.80)\end{array}$ \\
\hline \multicolumn{9}{|l|}{ Membranes } \\
\hline ruptured & 1.00 & & - & & - & & 1.00 & \\
\hline intact & 1.35 & $\begin{array}{l}(0.73 \\
2.50)\end{array}$ & - & & - & & 1.06 & $\begin{array}{l}(0.54 \\
2.09)\end{array}$ \\
\hline \multicolumn{9}{|l|}{ Anemia } \\
\hline Ante-partum hemoglobine> 11 mg/dl & 1.00 & & - & & - & & 1.00 & \\
\hline Ante-partum hemoglobine $<=11 \mathrm{mg} / \mathrm{dl}$ & 1.76 & $\begin{array}{l}(0.98 \\
3.16)\end{array}$ & - & & - & & 2.73 & $\begin{array}{l}(1.43, \\
5.23)\end{array}$ \\
\hline \multicolumn{9}{|l|}{ Cervical dilation on admission } \\
\hline up to $3 \mathrm{~cm}$ & 1.00 & & - & & - & & 1.00 & \\
\hline $4-7 \mathrm{~cm}$ & 3.62 & $\begin{array}{c}(0.51 \\
25.77)\end{array}$ & - & & - & & 4.60 & $\begin{array}{l}(0.70 \\
30.38)\end{array}$ \\
\hline$>7 \mathrm{~cm}$ & 3.67 & $\begin{array}{l}(0.47 \\
28.62)\end{array}$ & - & & - & & 6.34 & $\begin{array}{l}(0.87 \\
45.94)\end{array}$ \\
\hline \multicolumn{9}{|l|}{ Intra-partum } \\
\hline \multicolumn{9}{|l|}{ Delivery } \\
\hline Spontaneous delivery & - & & 1.00 & & 1.00 & & 1.00 & \\
\hline vaginal delivery with instruments & - & & 1.37 & $\begin{array}{l}(0.13 \\
14.22)\end{array}$ & 1.35 & $\begin{array}{l}(0.11 \\
15.87)\end{array}$ & 3.59 & $\begin{array}{c}(0.35 \\
36.79)\end{array}$ \\
\hline \multicolumn{9}{|l|}{ Episiotomy } \\
\hline no & - & & 1.00 & & 1.00 & & 1.00 & \\
\hline yes & - & & 1.60 & $\begin{array}{l}(0.97 \\
2.63)\end{array}$ & 1.55 & $\begin{array}{l}(0.94 \\
2.56)\end{array}$ & 1.72 & $\begin{array}{l}(0.69 \\
4.30)\end{array}$ \\
\hline \multicolumn{9}{|l|}{ Labor augmentation } \\
\hline no & - & & 1.00 & & 1.00 & & 1.00 & \\
\hline yes & - & & 1.77 & $\begin{array}{l}(1.11, \\
2.81)\end{array}$ & 1.94 & $\begin{array}{l}(1.17 \\
3.20)\end{array}$ & 2.37 & $\begin{array}{l}(1.14 \\
4.93)\end{array}$ \\
\hline \multicolumn{9}{|l|}{ Complete placenta expulsion } \\
\hline yes & - & & 1.00 & & 1.00 & & 1.00 & \\
\hline no & - & & 1.32 & $\begin{array}{l}(0.55 \\
3.16)\end{array}$ & 2.91 & $\begin{array}{l}(0.56 \\
15.07)\end{array}$ & 21.68 & $\begin{array}{c}(4.41 \\
106.54)\end{array}$ \\
\hline \multicolumn{9}{|l|}{ Vaginal tears } \\
\hline no & - & & 1.00 & & 1.00 & & 1.00 & \\
\hline yes & - & & 3.37 & $\begin{array}{l}(0.59 \\
19.41)\end{array}$ & 1.70 & $\begin{array}{l}(0.79 \\
3.67)\end{array}$ & 2.27 & $\begin{array}{l}(0.94 \\
5.50)\end{array}$ \\
\hline \multicolumn{9}{|l|}{ Fetal weights } \\
\hline$<3500 \mathrm{mg}$ & - & & 1.00 & & 1.00 & & 1.00 & \\
\hline Macrosomia (> $3500 \mathrm{mg}$ ) & - & & 1.35 & $\begin{array}{l}(0.85, \\
2.15)\end{array}$ & 1.59 & $\begin{array}{l}(1.01 \\
2.50)\end{array}$ & 0.99 & $\begin{array}{l}(0.53 \\
1.88)\end{array}$ \\
\hline \multicolumn{9}{|l|}{ Length of 1 st and 2 nd stage } \\
\hline$<1$ hour & - & & 1.00 & & 1.00 & & 1.00 & \\
\hline $1-2.9$ hours & - & & 2.42 & $(1.15,5.06)$ & 2.45 & $\begin{array}{l}(1.14 \\
5.26)\end{array}$ & 1.95 & $\begin{array}{l}(0.62, \\
6.15)\end{array}$ \\
\hline $3-4.9$ hours & - & & 3.25 & $\begin{array}{l}(1.62 \\
6.53)\end{array}$ & 3.77 & $\begin{array}{l}(1.86 \\
7.65)\end{array}$ & 4.93 & $\begin{array}{l}(1.55 \\
15.70)\end{array}$ \\
\hline $5+$ hours & - & & 2.66 & $\begin{array}{l}(1.22, \\
5.82)\end{array}$ & 3.12 & $\begin{array}{l}(1.44 \\
6.74)\end{array}$ & 5.75 & $\begin{array}{l}(1.73 \\
19.14)\end{array}$ \\
\hline
\end{tabular}

AMTSL 
Table 2 Adjusted multivariable logistic regression models for ante-partum and intra-partum risk factors associated with PPH (blood loss ? ??500 mL) for vaginal deliveries (Continued)

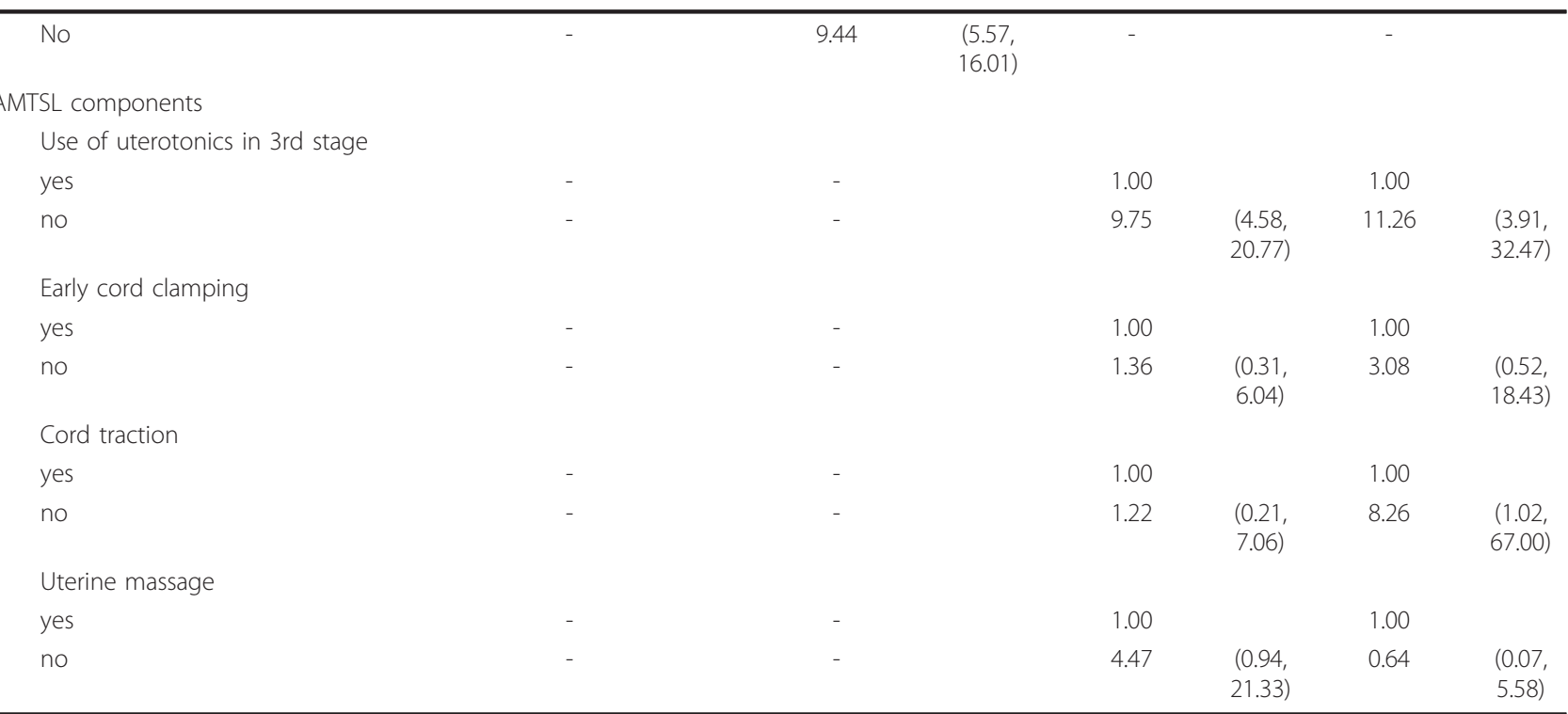

History of $\mathrm{PPH}$, non-use of cord traction, and retained placenta each had a predictive probability of $20 \%$ or higher.

We examined whether the percentage of women with $0,1,2,3$, or $4+$ significant risk factors differed between those who had PPH and those who did not (Figure 2). Although percentages appear different for those with 0 , 1,3 , and $4+$ factors, the difference was only significant among women with 3 risk factors. Post model probability estimates showed that by screening and diagnosing women with three risk factors, we can identify $10 \%$ of women who will develop PPH (Figure 3). Similarly, screening for 4 risk factors may identify $31 \%$ of women who will develop PPH.

Table 3 presents the relative sensitivity, specificity, likelihood ratio, and percent correctly classified for

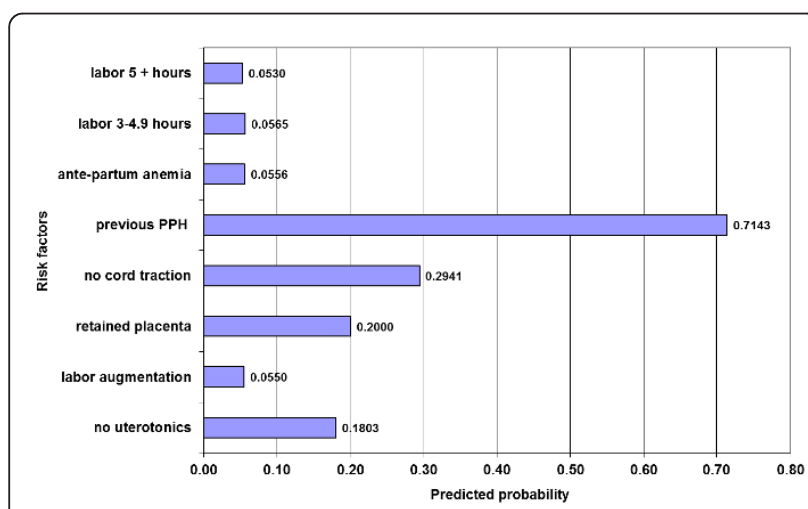

Figure 1 Predicted probability for risk factors significantly associated with $\mathrm{PPH}$ women with $1,2,3$, or $4+$ risk factors for $\mathrm{PPH}$. As the number of identified risk factors increases, so does percentage correctly classified. Perhaps because of the low incidence of PPH in the study population, the likelihood ratios are low for all risk factors. Women with $4+$ identifiable risk factors had an LR of above 12 .

Figure 4 displays the relative utility of screening women with 1, 2, 3, or 4+ significant risk factors for $\mathrm{PPH}$. Sensitivity, or the proportion of true positives, is high for using a screening cut point of 1 or 2 risk factors. However, the specificity, or proportion of true negatives, is low at $9 \%$ and $47 \%$ respectively. This means that if 1 risk factor was used as a cut point, $100 \%$ of those who would go on to have PPH would be captured. However, only $9 \%$ of those identified as positive would

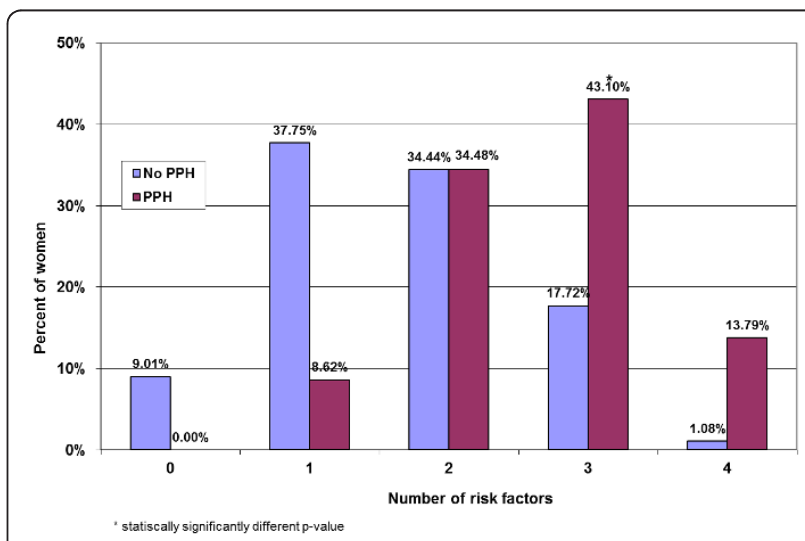

Figure 2 Number of statistically significant risk factors for PPH among women with vaginal deliveries. 


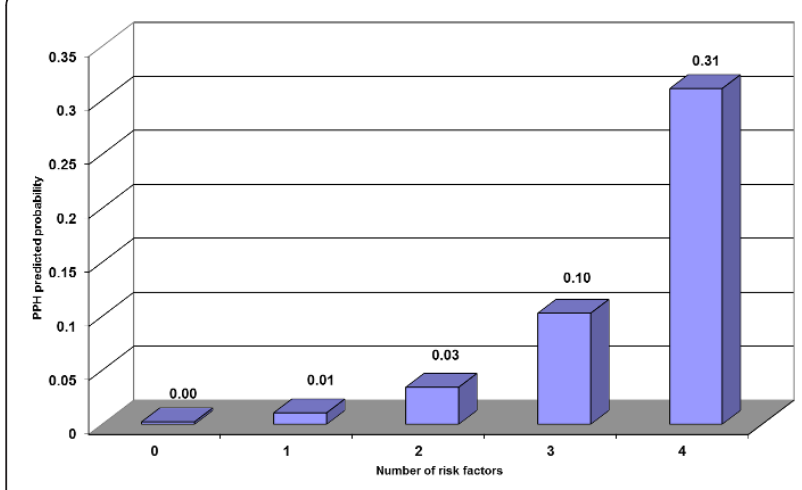

Figure 3 Predicted probability of developing PPH according to number of statistically significant risk factors.

actually be positive. Thus you would have many people who would be screened as at risk who in reality may not be. Increasing the cut point to 2 risk factors would decrease sensitivity only marginally, but would increase specificity to $47 \%$. Similarly, using 3 risk factors as a cut point would result in few false positives, but would also decrease sensitivity, meaning that some cases would be missed.

\section{Discussion}

Results of this study show that most demographic and ante-partum risk factors have little association with development of $\mathrm{PPH}$, with the exception of history of $\mathrm{PPH}$, low hemoglobin, and high usage of ANC. In addition, the predictive probability of ante-partum and intra-partum risk factors for PPH is low, although women with four or more identified risk factors had a predictive probability of over $30 \%$. This probability is higher than those observed by Tsu in Zimbabwe, and indicates that perhaps prediction of $\mathrm{PPH}$ is more significantly influenced by ante-partum variables [28].

The results of this analysis confirm our hypothesis that in vaginal, singleton deliveries, both ante-partum and intra-partum factors are associated with the incidence of $\mathrm{PPH}$, but these associations are not predictive. Predictive probability of PPH based on any risk factor remains low. The exception is history of $\mathrm{PPH}$, which had a predictive probability of $70 \%$ for incidence of $\mathrm{PPH}$. A high number of antenatal care visits was also associated with increased risk, likely because this serves as a marker for high-risk pregnancies. The utility of screening based on number of risk factors should be considered in conjunction with benefits of positively identifying all possible cases, and costs of over treating.

The findings of this study indicate that AMTSL significantly reduces the risk of PPH. AMTSL has been recommended as a routine management for vaginal deliveries in hospital settings [30,31], but it is rarely used in Egyptian hospitals. An analysis of the management of the third stage of labor in an Egyptian teaching hospital showed that only $15 \%$ of the women during the study period received correct AMTSL [32].

To our knowledge, this is the first analysis to examine the utility of each component of AMSTL separately. Our analysis of the components of AMTSL indicates that nonuse of uterotonics in AMTSL had the strongest association with increased odds of PPH after adjustment. Cord traction was also significantly associated with PPH after controlling for other components. Uterine massage and early cord clamping, however, appear to have no independent effect on risk of $\mathrm{PPH}$, which could be due to a lack of variability between each component. We investigated the variability of early cord clamping and cord traction and found that there were some women who received one and not the other. As a result, we decided to include both components in the model.

This touches on an overall limitation of this analysis. As many of the identified risk factors are correlated with one another, collinearity of the variables may have biased our inferences. This limitation would likely lead to conservative effect estimates, as we may be over controlling for related factors. In order to account for covariance, we used robust estimator of standard errors.

Low predictive probability values may have been the result of very low incidence of $\mathrm{PPH}$ in the study; the incidence of PPH in the study hospitals was 3.7\%. Administration of uterotonics and AMTSL in the study hospitals likely contributed to the low rate of PPH.

Despite a 52\% reduction in the Egyptian maternal mortality ratio (MMR) during the 1990s, PPH remained the main cause of death. According to the National Maternal Mortality Study [33], primary PPH alone was responsible for $27 \%$ of all maternal deaths, making it the single most important cause of maternal death in Egypt. High parity,

Table 3 Specificity and sensitivity criteria for postpartum hemorrhage

\begin{tabular}{lcccc}
\hline Number of risk factors & Sensitivity (\%) & Specificity (\%) & Likelihood ratio & \% correctly classified \\
\hline 1 & 100.00 & 9.01 & 1.10 & 12.66 \\
2 & 91.38 & 46.76 & 1.72 & 48.55 \\
3 & 56.90 & 81.20 & 3.03 & 80.22 \\
$4+$ & 13.79 & 98.92 & 12.76 & 95.5 \\
\hline
\end{tabular}




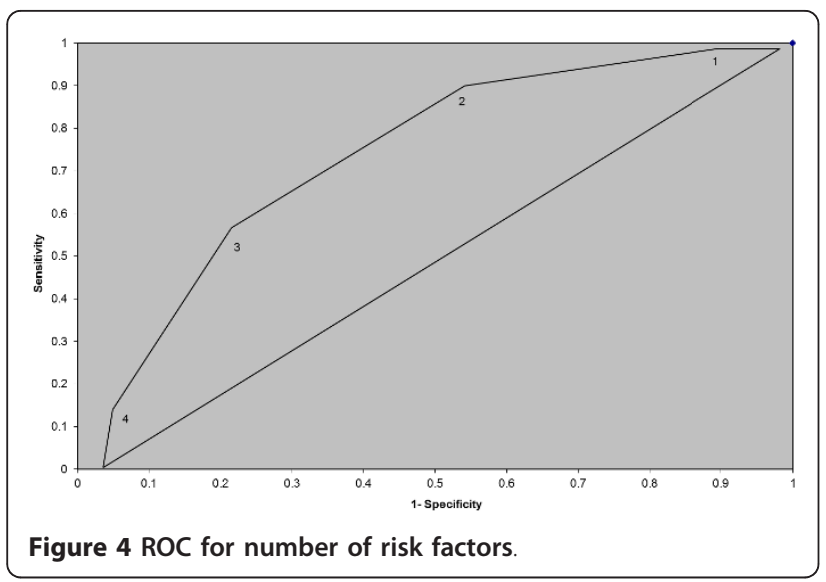

low socio-economic status of women, lack of skilled birth attendants, and mismanagement of $\mathrm{PPH}$ contribute to high maternal deaths in Egypt [34].

This study advances knowledge on the utility of screening for PPH in a clinical setting. This research has primary implications for screening and subsequent management of those at highest risk. Many of the identified risk factors cannot be prevented or altered, but women who present for delivery with these factors can be closely monitored, and when possible, intra-partum interventions that are significant risk factors should be avoided.

\section{Conclusion}

While no single risk factor or combination thereof can reliably predict risk of hemorrhage after delivery, combinations of risk factors can be used for screening and management. Given the limited utility of screening for $\mathrm{PPH}$, program planners and policy makers need to focus on the development and enforcement of protocols for prevention and treatment of $\mathrm{PPH}$ by considering the capacity and limitations of each context. The need for further research and policy work surrounding prevention efforts is especially important due to the low predictability of $\mathrm{PPH}$.

\section{Acknowledgements}

The authors wish to thank Ashley Fraser.

\section{Author details}

${ }^{1}$ Bixby Center for Population, Health and Sustainability, School of Public Health, University of California at Berkeley, 229 Warren Hall, UC-Berkeley, Berkeley, CA 94720-7360, USA. ºbstetrics and Gynecology Department, Faculty of Medicine, Ain Shams University, Abbasia, Cairo, Egypt. ${ }^{3}$ Venture Strategies Innovations, 2115 Milvia Street Suite 4A, Berkeley, CA 94704, USA.

\section{Authors' contributions}

NP designed the initial intervention, conceptualized the analysis, conducted data analysis, and was the primary author for the original study and the current study. SH was the co-investigator for this study and the original study, and contributed to the conceptualization of the study. SB helped in the writing of several iterations of the manuscript, and prepared the manuscript for publication. DK participated in data analysis and interpretation of results. FV conducted the literature review regarding PPH risk factors. $\mathrm{MH}$ reviewed the data analysis and interpretation and revised the manuscript. All authors have read and approved the final manuscript.

\section{Competing interests}

The authors declare that they have no competing interests.

Received: 26 August 2011 Accepted: 28 November 2011

Published: 28 November 2011

\section{References}

1. Khan KS, Wojdyla D, Say L, Gulmezoglu AM, Van Look PF: WHO analysis of causes of maternal death: a systematic review. Lancet 2006, 367(9516):1066-1074.

2. Magann EF, Evans S, Hutchinson M, Collins R, Howard BC, Morrison JC: Postpartum hemorrhage after vaginal birth: an analysis of risk factors. South Med J 2005, 98(4):419-422.

3. Al-Zirqi I, Vangen S, Forsen L, Stray-Pedersen B: Prevalence and risk factors of severe obstetric haemorrhage. BJOG-an International Journal of Obstetrics and Gynaecology 2008, 115(10):1265-1272.

4. Oyelese Y, Ananth CV: Postpartum Hemorrhage: Epidemiology, Risk Factors, and Causes. Clinical Obstetrics and Gynecology 2010, 53(1):147-156.

5. Magann EF, Doherty DA, Briery CM, Niederhauser A, Chauhan SP, Morrison JC: Obstetric characteristics for a prolonged third stage of labor and risk for postpartum hemorrhage. Gynecologic and Obstetric Investigation 2008, 65(3):201-205.

6. Combs CA, Murphy EL, Laros RK Jr: Factors associated with postpartum hemorrhage with vaginal birth. Obstet Gynecol 1991, 77(1):69-76.

7. Kavle JA, Stoltzfus RJ, Witter F, Tielsch JM, Khalfan SS, Caulfield LE: Association between anaemia during pregnancy and blood loss at and after delivery among women with vaginal births in Pemba Island, Zanzibar, Tanzania. Journal of Health Population and Nutrition 2008, 26(2):232-240.

8. Sheiner E, Sarid L, Levy A, Seidman DS, Hallak M: Obstetric risk factors and outcome of pregnancies complicated with early postpartum hemorrhage: a population-based study. J Matern Fetal Neonatal Med 2005, 18(3):149-154.

9. Marchant S, Alexander J, Thomas P, Garcia J, Brocklehurst P, Keene J: Risk factors for hospital admission related to excessive and/or prolonged postpartum vaginal blood loss after the first $24 \mathrm{~h}$ following childbirth. Paediatr Perinat Epidemiol 2006, 20(5):392-402.

10. Geller SE, Goudar SS, Adams MG, Naik VA, Patel A, Bellad MB, Patted SS, Edlavitch SA, Moss N, Kodkany BS, et al: Factors associated with acute postpartum hemorrhage in low-risk women delivering in rural India. International Journal of Gynecology \& Obstetrics 2008, 101(1):94-99.

11. Lertbunnaphong $T$, Leetheeragul J, Thitadilok W: Risk factors of primary postpartum hemorrhage in Siriraj Hospital. Siriraj Medical Journal 2010, 62(5), unpaginated.

12. Sebire NJ, Jolly M, Harris J, Regan L, Robinson S: Is maternal underweight really a risk factor for adverse pregnancy outcome? A population-based study in London. Bjog 2001, 108(1):61-66.

13. Bateman BT, Berman MF, Riley LE, Leffert LR: The Epidemiology of Postpartum Hemorrhage in a Large, Nationwide Sample of Deliveries. Anesthesia and Analgesia 2010, 110(5):1368-1373.

14. Rueangchainikhom W, Srisuwan S, Prommas S, Sarapak S: Risk Factors for Primary Postpartum Hemorrhage in Bhumibol Adulyadej Hospital. Journal of the Medical Association of Thailand 2009, 92(12):1586-1590.

15. Sosa CG, Althabe F, Belizan JM, Buekens P: Risk Factors for Postpartum Hemorrhage in Vaginal Deliveries in a Latin-American Population. Obstetrics and Gynecology 2009, 113(6):1313-1319.

16. Karoshi M, Keith L: Challenges in Managing Postpartum Hemorrhage in Resource-poor Countries. Clinical Obstetrics and Gynecology 2009, 52(2):285-298.

17. Geelhoed D, Visser L, Agordzo P, Asare K, van Leeuwen JS, van Roosmalen J: Active versus expectant management of the third stage of labor in rural Ghana. Acta Obstet Gynecol Scand 2002, 81(2):172-173.

18. Stones RW, Paterson CM, Saunders NJ: Risk factors for major obstetric haemorrhage. Eur J Obstet Gynecol Reprod Biol 1993, 48(1):15-18.

19. Bais JM, Eskes M, Pel M, Bonsel GJ, Bleker OP: Postpartum haemorrhage in nulliparous women: incidence and risk factors in low and high risk 
women. A Dutch population-based cohort study on standard $(>$ or $=$ $500 \mathrm{ml}$ ) and severe $(>$ or $=1000 \mathrm{ml}$ ) postpartum haemorrhage. Eur J Obstet Gynecol Reprod Biol 2004, 115(2):166-172.

20. Combs CA, Laros RK Jr: Prolonged third stage of labor: morbidity and risk factors. Obstet Gynecol 1991, 77(6):863-867.

21. Magann EF, Evans S, Chauhan SP, Lanneau G, Fisk AD, Morrison JC: The length of the third stage of labor and the risk of postpartum hemorrhage. Obstet Gynecol 2005, 105(2):290-293.

22. Selo-Ojeme DO, Okonofua FE: Risk factors for primary postpartum haemorrhage. A case control study. Arch Gynecol Obstet 1997, 259(4):179-187.

23. St George L, Crandon AJ: Immediate postpartum complications. Aust N Z J Obstet Gynaecol 1990, 30(1):52-56.

24. Goudar SS, Chakraborty H, Edlavitch SA, Naik VA, Bellad MB, Patted SS, Patel A, Moore J, McClure EM, Hartwell T, et al: Variation in the postpartum hemorrhage rate in a clinical trial of oral misoprostol. Journal of Maternal-Fetal \& Neonatal Medicine 2008, 21(8):559-564.

25. Magann EF, Doherty DA, Briery CM, Niederhauser A, Morrison JC: Timing of placental delivery to prevent post-partum haemorrhage: lessons learned from an abandoned randomised clinical trial. Australian \& New Zealand Journal of Obstetrics \& Gynaecology 2006, 46(6):549-551.

26. Lu MC, Muthengi E, Wakeel F, Fridman M, Korst LM, Gregory KD: Prolonged second stage of labor and postpartum hemorrhage. Journal of MaternalFetal \& Neonatal Medicine 2009, 22(3):227-232.

27. Mousa HA, Cording V, Alfirevic Z: Risk factors and interventions associated with major primary postpartum hemorrhage unresponsive to first-line conventional therapy. Acta Obstetricia Et Gynecologica Scandinavica 2008, 87(6):652-661.

28. Tsu VD: Antenatal screening: its use in assessing obstetric risk factors in Zimbabwe. J Epidemiol Community Health 1994, 48(3):297-305.

29. Prata N, Hamza S, Gypson R, Nada K, Vahidnia F, Potts M: Misoprostol and active management of the third stage of labor. Int I Gynaecol Obstet 2006, 94(2):149-155.

30. Prendiville WJ: The prevention of post partum haemorrhage: optimising routine management of the third stage of labour. Eur J Obstet Gynecol Reprod Biol 1996, 69(1):19-24.

31. Management of the third stage of labour to prevent postpartum hemorrhage. J Obstet Gynaecol Can 2003, 25(11):952-955.

32. Cherine M, Khalil K, Hassanein N, Sholkamy H, Breebaart M, Elnoury A: Management of the third stage of labor in an Egyptian teaching hospital. Int J Gynaecol Obstet 2004, 87(1):54-58.

33. Hamza S: The Maternal Mortality:Egyptian National Maternal Mortality Study. Ain Shams Journal of Obstetrics and Gynecology 2005, 2:306-307.

34. Abdel-razik MS: Postpartum haemorrhage as a public health problem. $J$ Egypt Soc Obstet Gynecol 1991, 17(1):51-61.

\section{Pre-publication history}

The pre-publication history for this paper can be accessed here: http://www.biomedcentral.com/1471-2393/11/97/prepub

doi:10.1186/1471-2393-11-97

Cite this article as: Prata et al: Inability to predict postpartum hemorrhage: insights from Egyptian intervention data. BMC Pregnancy and Childbirth 2011 11:97.

\section{Submit your next manuscript to BioMed Central and take full advantage of:}

- Convenient online submission

- Thorough peer review

- No space constraints or color figure charges

- Immediate publication on acceptance

- Inclusion in PubMed, CAS, Scopus and Google Scholar

- Research which is freely available for redistribution

Submit your manuscript at www.biomedcentral.com/submit
Biomed Central 